solely from theoretical considerations) appears to be the presence of a mass of gangrenous organic matter immediately opposite a granulating and highly absorbent surface. For this reason in our recent case we kept outside the indiarubber ligature a loose skein of cotton yarn, about the same thickness as the ligature, and well soaked in carbolic oil. This was renewed three times a day, and a piece of lint kept well wetted with a permanganate solution prevented any offensive odour. On the third day it became evident that the ligature was no longer acting, and on examination it was found to be quite loose. You may remember the simple way in which this difficulty was combated. A slender rod of ivory, one millimetre in thrckness, was passed through the ligature circle and twisted round a few times, in the manner in which a ready tourniquet is made from a handkerchief tied round a limb with a stick twisted through it. These ivory rods can be had of various thicknesses in the shanks of ivory crochet-needles. Ivory is, I think, the best material, on account of its strength, lightness, smoothness, and rigidity; and by this simple means ligatural pressure can be kept up to the very last to any degree of tightness required. On the fifth day the mass dropped off, leaving a surface which healed up kindly; and, with some constitutional treatment for the syphilitic taint, the patient made a good recovery.

I would particularly impress upon you that at the time of application, and while it is cutting through the skin, the ligature is painful. For this reason, just before commencing, we injected hypodermically a quarter of a grain of acetate of morphia in the neighbourhood of the operation, a procedure which much assisted the anæsthesia, and reduced subsequent local pain, by keeping the patient throughout the whole day of the operation in a drowsy, quiescent state.

\section{THE SPIRIT RATION.}

By SURGEON-GENERAL W. C. MACLEAN, M.D., C.B., PROFESSOR OF MILITARY MEDICINE, ARMY MEDICAL SCHOOL, NBTLEY.

Sone of the readers of THE LANCET are aware that on the 16th February I gave a lecture at the Royal United Service Institution on the Sanitary Precautions to be observed in the Moving and Camping of Troops in Tropical Regions. The subject of the issue of spirits to troops came fairly within the scope of my subject, and I accordingly offered some observations on it. So many communications have since been addressed to me by officers who take an interest in this subject that I venture to ask for space for a few remarks on it. In the lecture $I$ thus expressed myself :-

"Spirits.-If there be any point of military hygiene that may now be regarded as settled beyond doubt or cavil it is this, that spirits are not only not helpful, but are hurtful to the marching soldier, everywhere I believe, but nowhere more so than in hot climates. The evidence on this point is overwhelming. The medical officers of the French army who have had great experience in the arduous campaigns in Algeria denounce the spirit ration as hurtful; and Dr. Morache, already quoted as a high authority on military hygiene, declares that unless coffee had taken the place of spirits it would have been impossible for the troops to surmount the fatigues of what he justly calls ces pénibles campagnes. Were I the medical chief of an army destined to take the field in a tropical climate, not a drop of spirits should, with my consent, accompany it, save what the requirements of the ambulance service demanded. The evidence shows that wherever soldiers, by accident or design, have been cut off from the use of spirits on marches, on active service, in temperate climates exposed to wet and cold, or in the tropics to ardent heat, or in laborious sieges, they have maintained their health, spirits, and discipline far better than when the oncedeemed indispensable grog was in daily use. My colleague, Dr. Parizes, and the late Count Wollowicz, in a series of careful experiments on the use of alcohol carried on at Netley, and published in the "Transactions of the Royal Society, have placed on a sure scientific basis what was before a matter of observation, and have established that alcohol, far from increasing the power of bearing fatigue, even when given in a quantity which many spirit-drinkers would deem within the limits of moderation, lessens muscular force, and a quantity in excess of this, it was shown, entirely destroyed the power of work. The reason, Dr. Parkes says, was twofold. There was, in the first place, narcosis and blunting of the nervous system-the will did not properly send its commands to the muscles, and the muscles did not respond to the will; and, secondly, the action of the heart was too much increased, and induced palpitation and breathlessness which put a stop to labour. The inference was, 'that even any amount of alcohol, although it did not produce symptoms of narcosis, would act injuriously by increasing unnecessarily the action of the heart, which the labour alone had sufficiently augmented.' For fatigue, rest and food are the proper reme. dies. Alcohol given alone under such circumstances can only stimulate the already nearly exhausted heart to fresh exertion. Under some very exceptional circumstances it may be a matter of absolute necessity to do this, but even then we must follow Dr. Parkes's rule-namely, to give spirits in small quantity, not more than an ounce of brandy, and if possible it should be mixed with Liebig's meat extract, which has a great power of removing the sense of fatigue. Dr. Parkes even gives a formula, which is worth bearing in mind, for use under such circumstances; as for example, when troops, after a fatiguing march, are obliged to engage the enemy without time for rest and food, he advises two ounces of red claret wine, with two teaspoonfuls of Liebig's extract, in half a pint of water. Wine not being available, half an ounce of brandy or rum would be a good substitute.

"I cannot leave this important subject without adding that for twelve years 1 have, at Netley, had unrivalled opportunities of studying the effects of habitual dram-drinking on the persons of our soldiers, and I add my testimony to the immense weight of evidence accumulated by medical men in civil and military life, to the effect that alcohol is one of the most active agents in causing degeneration of the human tissues - in other words, disease, premature decay, and death. If this be true, as I believe it is, those officers who, by precept and example, strive to wean their men from the practice of this our national vice may with truth be said to be engaged in a patriotic work, and to deserve well of their country. Tet me ask you to look at this alcohol question from another point of view. I hold in my hand a copy of a work known, I dare say, to many present-viz., 'The Sepoy War' beino the private journal of General Sir Hope Grant, edited by Captain Knollys, R.A. A modest record of very distinguished service. At page 108 we have the following passage, referring to the siege of Delhi :- In order to fight to perfection, British soldiers must eat, and they must drink. Would they drank a little less. There never appears to have been any lack of provisions, and vast quantities of spirituous liquors fell into our men's hands. Drunkenness became fearfully rife, entailing with it increased sickness, as well as a relaxation of discipline, which it was necessary to repress with an iron hand.' We all know the stake played for at Delhi. It was the Empire of India. Mark how alcohol put the issue in peril. Mark also that from this danger we were saved only by that unrivalled power of maintaining discipline which British officers have shown at all times, in all places, and under all circumstances.

"Coffee.-It is almost superfluous to add that the best substitute for alcohol is coffee or tea. The French military medical officers vaunt, and with justice, the superiority of the light wines of their own country over the more strongly branded wines of Spain and Portugal; and they point to the fact that, when used in moderation, the aromatic principles and the various salts they contain exercise an effect on the digestive organs which is alike wholesome and agreeable. With all this the best of them give a decided preference to coffee. Morache, in particular, is emphatic in his testimony, and is even eloquent in its praise as an article of diet, a safe stimulant, an aid to digestion, and an efficient refreshment under fatigue. Coffee forms no part of the ration of the French soldier in time of peace; but Morache does not hesitate to urge its issue instead of brandy, and he instances certain regiments in which the custom of substituting coffee for the morning petit verre had much advanced the cause of temperance. 
"That a cup of hot coffee is the best preparation for the fatignes of a march is indisputable, and it should never be omitted. It is much better that the men should have it before leaving their ground, and not at the half-way halt as was common in my time in India: it invigorates them at starting, protects, particularly the young soldiers, against the griping abdominal pains to which they are subject, particularly in the dark and chilly bour preceding the dawn; and the vigour it imparts helps the system to resist the miasm which at this hour is most freely evolved from the soil. It is worthy of remark that coffee was first issued to European troops for this very purpose, on the advice of the great Larrey, during Napoleon's Egyptian campaign."

It is said by some that my condemnation of spirits in the above passage "is too sweeping"; that to many, or at least to some, "alcohol in moderation is a wholesome and useful refreshment"; and, in the pages of THE LANCET, that " common sense and a knowledge of men's habits are sometimes more useful guides than the results of science," and on this ground the issue of a moderate allowance of alcohol to soldiers at the end of a march is justified. I may be permitted to say in passing, that $I$ am not a temperance fanatic; I am not a "total abstainer" from the temperate use of wine and beer, although, perhaps fortunately for myself, so constituted as to be unable without swift punishment to use spirits.

In discussing a question of this kind affecting the interests and well-being of an army, we must disregard individual peculiarities- what suits this man or that man,and look solely to what is best for the mass. It is a legitimate part of the argument to point to the fact that alcohol is the curse of the army wherever it serves: the fruitful parent of crime and disease. The same is said every day, and with truth, of men in civil life, although the amount of mischief under both heads, for obvious reasons, is more easily measured in military life. If it can be shown that in coffee ${ }^{1:}$ tea we have an article of refreshment that is equal, or nearly equal, to alcohol, it is surely an object of immense importance to encourage the use of the one that, according to the well-worn line, "cheers but not inebriates." It is quite true, as the writer in ThE LANCET, already quoted, puts it, that a 42nd Highlander "would as soon drink red ink as red wine," and that during his march the prospect of a glass of whisky would be very pleasing "to look forward to"; and I am prepared to go a little beyond this, and to add that if he had the hope of two or three more on the top of the first, he would think it something still better "to look forward to." The question is not what from the pernicious effect of habit the soldier likes, but what experience and, if you like, "common sense," shows is best for him and the State, whose costly and valuable servant he is. This is the principle that should govern all our dealings with ouestions affecting health and discipline. Now, disregardin exceptional cases, I maintain that the evidence in favour o hot tea or coffee as a refreshment after fatigue, and their superiority in this respect over alcohol, is overwhelming. I have referred in the quotation from my lecture, given above, to the experience gained in the trying Algerian campaigns. Looking back to my experience among sportsmen in India, I cannot recall a single example of a spirit-drinker who was able for any length of time to expose himself with impunity to the sun, while it is notorious that abstainers from alcohol are capable of doing so, as a general rule, to a great extent.

In my lecture (when on the subject of sunstroke) I gave an instructive example. The troops holding Canton were called on to turn out at midday. A battery of artillery had more cases of insolation than all the rest of the force put together, the reason being that the canteen was opened by the officer commanding with the "good intention" of "fortifying" his men with a glass of grog before starting. My able friend, Staff Surgeon-Major Becker, an accurate observer, and in this case an eje-witness, is my authority for this pregnant fact.

I cannot agree with the writer in The Lancet already referred to in his reference to science in connexion with this subject. As I have elsewhere said, science in this only confirms observation. The experiments of Dr. Parkes and the late Count Wollowicz, prove to a demonstration that even in temperate climates alcohol is a hindrance and not an aid to work. As many of my friends know, I am in the habit of spending my autumn vacation on the mountains of the north, and although not quite so young as I have been, I have again and again walked my whisky-drinking companions, friends, keeper, and gillie, to a standstill. In one word, alcohol in moderation may help a man to put on a "spurt," but it is no aid to a hard day's work; and I devoutly hope that the day is not distant when a War Minister will have the courage to decree that the issue of spirits to the soldier shall cease and determine. Netley.

\section{ON THE}

\section{VALUE OF THE STAINING PROCESS IN THE} HISTOLOGY OF THE MORBID BRAIN.

\section{BY HERBERT C. MAJOR, M.B. EDIN.,}

ASSISTANT MEDICAL OFFICER, WEST RIDING ASYLUM, WAKEFIELD.

Thar the various tissues of the body are, in health, susceptible to the action of staining fluids to a different degree, is a point which has long been recounised by histologists, and one which has led, in the hands of many, to great practical results. But true as this is with respect to different tissues, equally true is the point and equally valuable the fact as applied to the same tissue under various morbid conditions. And yet it may be doubted whether those who have set themselves to examine pathological changes have availed themselves fully of the advantage thus afforded them. I refer more especially to the histology of the brain and the morbid conditions which that organ presents in various forms of insanity. In this great field of inquiry, so full of new and all-absorbing interest, it is of the utmost importance that every fact should he brought to bear, and each so directed as to act to the greatest advantage.

In no other department of histological research has the process of staining been more widely used or attended with greater benefit; but, nevertheless, $I$ believe, and it is my present object to show, that its advantages may be still further extended.

That the grey cortical layer of the cerebrum is, under certain circumstances, with difficulty stained by the colouring solution employed, is a fact which has not, and indeed which could not escape observation. But there are conditions altogether independent of the state of the cerebral substance which may bring about such a result, while, on the other hand, there are others which favour the staining process; and all these it is necessary well to weigh and consider, in order to guard against the fallacies they might induce. By means of a strong staining fluid, it need scarcely be said, any nervous tissue may be deeply stained, and the same result will be obtained by prolonged immersion in a weaker fluid. But further, the susceptibility of the braintissue to the colouring solution will greatly depend on the method of hardening employed. It is a well-known fact that when preserved in chromic acid, the subsequent staining of the cerebral substance is less rapid and intense than when spirit has been employed; and hence it would happen that sections of the same tissue, on which similar staining fluid had been allowed to act and for equal time, might still vary considerably in depth of colouration, provided the hardening method employed were different in each case. I need hardly point out how, under these circumstances, any inference drawn from the relative intensity of the staining must be entirely fallacious and misleading. But as the fallacy is great if due precautions are not taken, so is the information derived weighty and valuable if uniform conditions are observed. 'To bring the matter to a practical issue: I believe that the method of staining the brainsubstance, as usually pursued in investigating pathological change, is faulty; that, due attention being paid to observe uniformity in the hardening process and in the thickness of the sections, the object should then be, not to leave the sections in the staining fiuid till "sufficiently coloured," but, having first decided by experiment the time required to colour a section of healtby brain with a solution of given strength, to allow the latter such time and no longer for its action in all cases. I have at the present moment before me sections representing cases of acute mania, epilepsy, general paralysis of the insane, and senile 